\title{
Distance to hospital is not a risk factor for emergency colon cancer surgery
}

\author{
Niillas Blind $^{1}$ (D) . Karin Strigård ${ }^{1}$. Ulf Gunnarsson ${ }^{1}$ - Fredrik Brännström ${ }^{1}$
}

Accepted: 29 April 2018 / Published online: 24 May 2018

(C) The Author(s) 2018

\begin{abstract}
Purpose The purpose of this study is to see if the distance to a hospital performing colon cancer surgery is a risk factor for emergency surgical intervention and to determine the variability between defined but demographically divergent catchment areas. Methods Data on patients living in Västerbotten County who underwent colon cancer surgery between 2007 and 2010 were extracted from the Swedish Colorectal Cancer Register (SCRCR). Of the 436 registrations matching these criteria, 380 patients were used in the analysis, and their distance to the nearest hospital providing care for colorectal cancer (CRC) was estimated using Google Maps ${ }^{\mathrm{TM}}$. The correlations between the risk for emergency surgery and the distance to a hospital, gender, age, income level and hospital catchment area were analysed in uni- and multivariate models.

Results Distance to the nearest hospital had no significant effect on the proportion of emergency operations for colon cancer. There was significant variability in risk for emergency surgery between hospital catchment areas, where the catchment areas of the university hospital and the most rural hospital had a higher proportion than the other local hospital catchment area (OR, 2.00 $(p=0.038)$ and $\mathrm{OR}, 2.97(p=0.005))$. These results were still significant when analysed with multivariate logistic regression (OR, $2.13(p=0.026)$ and $\mathrm{OR}, 3.05(p=0.013))$.

Conclusion Distance to a hospital performing colon cancer surgery had no effect on the proportion of emergency surgeries. However, a variability between defined catchment areas was seen. Future studies will focus on possible factors behind this variability.
\end{abstract}

Keywords Colon cancer $\cdot$ Emergency surgery $\cdot$ Distance $\cdot$ Rural

\section{Introduction}

In Sweden, the proportion of all colon cancer surgery performed as an emergency is $21.5 \%$ [1]. Patients having emergency surgery for colon cancer have worse short- and longterm survival rates than elective cases [2,3]. The most common reasons for emergency surgery are obstruction, perforation and bleeding [4], and tumour stage is often more advanced [5]. Various factors can prolong the time it takes to come to a diagnosis of colorectal cancer (CRC), including delay on the part of the patient and of their doctor [6, 7]. Persons living alone, for example, tend to seek healthcare at a later stage for symptoms suggestive of CRC [8], and socioeconomic status

Niillas Blind

niillas.blind@umu.se

1 Department of Surgical and Perioperative Sciences, Umeå University, SE-901 88 Umeå, Sweden also has an impact on delay of diagnosis and proportion of colon cancer surgery performed as an emergency $[9,10]$. Previous studies on survival in colon cancer have found lower survival rates among patients living in rural areas [11].

The county of Västerbotten in northern Sweden has 263,000 inhabitants [12] divided between 15 municipalities; the majority residing in two towns on the east coast. The municipalities inland are smaller and have a longer distance to travel to a hospital performing colorectal cancer surgery. One of the coastal towns has a university hospital and the other a local hospital. There is also a local hospital in the sparsely populated western part of the county. All three hospitals performed elective and emergency CRC surgery during the study period. This situation with three hospitals covering well-defined rural and urban areas makes Västerbotten a suitable model for investigating the relationship between demography and geography in the treatment of CRC. All patients undergoing surgery for colon cancer in Sweden are reported to the Swedish Colorectal Cancer Register (SCRCR) having a completeness of $99.5 \%$. Operations are classified by the 
surgeon as either emergency or elective. Emergency surgery is defined in the SCRCR as a procedure performed for medical reasons during an unplanned hospital admission.

Most healthcare providers in Sweden come under the national healthcare service, and this is especially true for cancer care. Hospitals have strict catchment areas based on county borders, and it is uncommon for patients to receive CRC healthcare in hospitals outside their own catchment area [13].

There has been a trend towards centralisation of CRC care based on the small differences in outcome reported between low- and high-volume surgeons and hospitals [14]. However, little is known about the impact of centralisation itself. One effect of centralisation could be that the longer distance that must be travelled to hospitals performing CRC surgery, increases the risk for emergency presentation of colon cancer.

The aim of this study was to see if a longer distance to a hospital providing surgical care for CRC is a risk factor for emergency surgery and to determine the variability of percentage emergency surgery between geographically defined catchment areas.

\section{Method}

Data on all patients who had undergone surgery for colon cancer in Västerbotten County 2007-2010 were retrieved from the SCRCR.

The address of each patient was obtained from the patient's hospital records. Google Maps ${ }^{\mathrm{TM}}$ was used to estimate the distance from each patient's home to the nearest hospital providing surgical care for CRC. Since the aim was to see if distance to a hospital providing CRC surgery was a risk factor for emergency colon cancer surgery, the distance from the patient address to the nearest such hospital was used also in the rare cases were the surgery actually was performed at another hospital.

Three hospitals were included: the university hospital on the coast (hospital A); the local hospital on the coast (hospital $\mathrm{B}$ ); and the rural local hospital inland (hospital C). There are differences in population density between these hospitals, with hospital A having 15.7, hospital B 8.9, and hospital C 1.0 inhabitants $/ \mathrm{km}^{2}$. Data were also collected regarding average income, age, gender and municipality population density.

To analyse the role of income level, the population was divided into two groups based on the mean income of the municipality of residence, since individual income details were not available. The two largest municipalities were also those with the highest mean incomes and thus formed the high-income group. The other 13 smaller municipalities formed the low-income group.

The population was further divided into three groups based on the population density of the municipality of residence. The largest municipality constituted a group on its own, two intermediary populated municipalities formed the second group and the remaining 12 formed the most sparsely populated group.

The population was divided into three groups according to age; the youngest quartile and the oldest quartile groups, with the two intermediary quartiles forming the reference group. The reason for this was that the relationship between age and the risk for emergency surgery was expected to be nonlinear with the youngest and/or the oldest age groups having divergent values. Since the relationship between distance to the hospital and risk for emergency surgery was not known, both a linear assumption (linear regression) and an arbitrary division into four groups based on quartiles (logistic regression) were tested.

To ensure that data on emergency priority were valid, 47 random records were checked by three colorectal surgeons, blinded and separated from each other, to see if the priority in the records matched the priority given in the register.

In the cases where data on priority were missing, a priority assessment was made retrospectively, based on the patient's records.

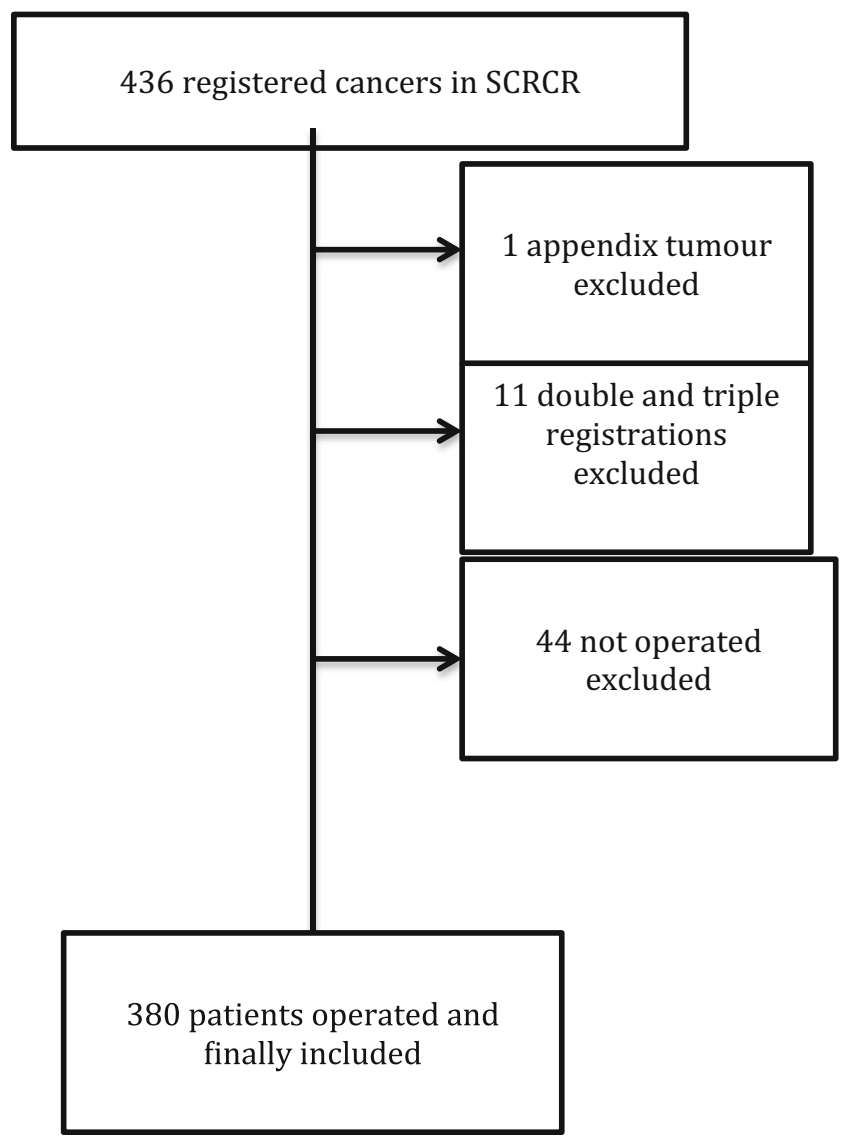

Fig. 1 Flow chart of patients retrieved from the SCRCR. Of the 380 patients finally included, 365 underwent resection surgery, 2 received a stent and 3 a stoma as emergency procedure, and the remaining had different surgical procedures 


\section{Proportion of colon cancer surgery performed as an}

emergency in Västerbotten County 2007-2010

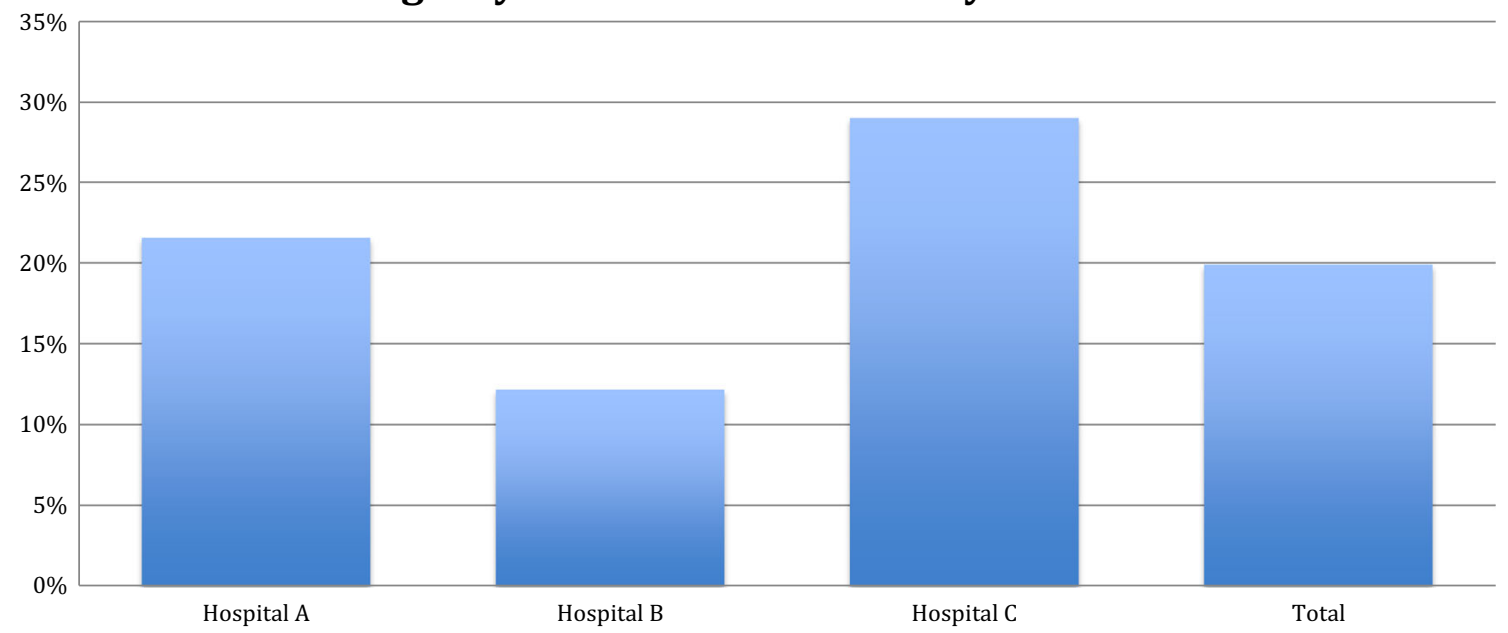

Fig. 2 Proportion of colon cancer surgery performed as an emergency in three different catchment areas in Västerbotten County. Hospital A, Umeå (University hospital); hospital B, Skellefteå (Local hospital); hospital C, Lycksele (Local hospital in rural area)

\section{Statistics}

Uni- and multivariate linear and logistic regressions were used. In the multivariate analyses, all variables were entered at the same time (force entry). Since the parameters describing income and catchment areas were both based on municipalities, they were not considered independent from each other and therefore not applied in the same multivariate models. All analyses were performed using STATA version 13.1 (StataCorp LP, College Station, TX, USA).

\section{Ethics}

Ethical approval for this study was obtained from the Regional Ethics Committee in Umeå (Dnr 2015/143-31).

\section{Results}

There were 436 registrations on 425 individuals from the defined time period in the SCRCR. Only the first operation was included for patients who had had surgery more than once. After exclusion of double and triple registrations, patients not operated on and a tumour of the appendix, 380 procures remained for analysis (Fig. 1).

Two of these three hundred eighty patients received a stent as a bridge to surgery, and three patients received a stoma before resection. In eight cases, priority was judged using the patient's records because data were missing in the register.
Table 1 Distance to hospital for different patient groups operated for colon cancer in Västerbotten County

\begin{tabular}{|c|c|c|c|}
\hline Number & & Mean distance $(\mathrm{km})$ & $p$ value \\
\hline \multicolumn{4}{|l|}{ Priority } \\
\hline $304 / 380$ & Elective & 32.63 & Ref \\
\hline $76 / 380$ & Emergency & 37.01 & 0.433 \\
\hline \multicolumn{4}{|c|}{ Estimation of surgeon } \\
\hline $318 / 380$ & Curative surgery & 33.82 & Ref \\
\hline $62 / 380$ & Palliative surgery & 31.58 & 0.748 \\
\hline \multicolumn{4}{|c|}{ Type of operation } \\
\hline $365 / 380$ & Resection surgery & 33.68 & Ref \\
\hline $15 / 380$ & Other surgery & 29.84 & 0.722 \\
\hline \multicolumn{4}{|l|}{ Age } \\
\hline $96 / 380$ & 1st quartile & 33.98 & 0.949 \\
\hline $185 / 380$ & 2nd-3rd quartiles & 33.63 & Ref \\
\hline $99 / 380$ & 4th quartile & 32.81 & 0.881 \\
\hline \multicolumn{4}{|l|}{ Gender } \\
\hline $205 / 380$ & Female & 34.22 & Ref \\
\hline $175 / 380$ & Male & 32.67 & 0.729 \\
\hline \multicolumn{4}{|c|}{ Population density } \\
\hline $138 / 380$ & High & 8.86 & Ref \\
\hline $123 / 380$ & Average & 16.41 & 0.044 \\
\hline $119 / 380$ & Low & 79.76 & 0.000 \\
\hline \multicolumn{4}{|l|}{ Income } \\
\hline $244 / 380$ & High & 10.93 & Ref \\
\hline $136 / 380$ & Low & 74.00 & 0.000 \\
\hline
\end{tabular}

Distance to a hospital performing CRC surgery for different patient groups in the CRC database for Västerbotten County 2007-2010 
In one of the forty-seven cases checked (2\%) by the three blinded surgeons, the priority (elective/emergency) noted in the records was considered not to match that in the register.

The mean age of the patients included was 72 years, and $53 \%$ were female. The quartiles for age were $0-66,67-72$, $73-78$ and 79-88 years. The quartiles for distance were 0 $3.49,3.5-13.79,13.8-51.19$ and $51.2-232 \mathrm{~km}$.

The mean distance to a hospital providing CRC surgery was $32.6 \mathrm{~km}$ (range, $0.1-231.6 \mathrm{~km}$ ). Of the patients included, 77 (19.89\%) had emergency surgery. In the 4th distance quartile, the mean distance was $93 \mathrm{~km}$, and in the $>90 \%$ group, the mean distance was $130 \mathrm{~km}$. The only significant difference in prevalence of emergency surgery was related to catchment area (Fig. 2). No difference was found concerning distance to hospital (Table 1). The results of the multivariate linear regression models did not reveal any relevant difference from the univariate models. There was no significant difference in the risk for emergency surgery between the high- and low-income groups (> 23,439 and $<22,856$ euro/year) (Table 2).

\section{Discussion}

Distance to the nearest hospital performing CRC surgery did not have an impact on the risk for emergency surgery for patients with colon cancer. This indicates that the distance to hospital does not affect the time passed between symptom presentation or diagnosis and surgery. With our current data set, it is not possible to make any absolute conclusions regarding extreme distances. However, we make the assessment that the distances calculated are relevant for European circumstances. An alternative interpretation is that difference in the delay to elective surgery does

Table 2 Risk factors for emergency surgery for colon cancer in Västerbotten County

\begin{tabular}{|c|c|c|c|c|c|c|c|c|}
\hline \multirow[t]{2}{*}{ Number } & & \multirow[t]{2}{*}{ Emergency surgery } & \multicolumn{3}{|l|}{ Univariate } & \multicolumn{3}{|l|}{ Multivariate } \\
\hline & & & Odds ratio & $95 \% \mathrm{CI}$ & $p$ value & Odds ratio & $95 \% \mathrm{CI}$ & $p$ value \\
\hline \multicolumn{9}{|l|}{ Distance } \\
\hline $91 / 380$ & 1st quartile & $20.8 \%$ & 1.48 & $0.70-3.11$ & 0.305 & 1.47 & $0.68-3.20$ & 0.332 \\
\hline $99 / 380$ & 2nd quartile & 15.2 & 1.00 & Ref & Ref & 1.00 & Ref & Ref \\
\hline $94 / 380$ & 3rd quartile & 20.2 & 1.42 & $0.67-2.99$ & 0.358 & 1.52 & $0.71-3.24$ & 0.281 \\
\hline $96 / 380$ & 4th quartile & 24.0 & 1.76 & $0.86-3.63$ & 0.123 & 1.26 & $0.55-2.92$ & 0.582 \\
\hline \multicolumn{9}{|c|}{ Distance $(90 \%)$} \\
\hline $339 / / 380$ & $<90$ th $(\%)$ & $19.5 \%$ & 1.00 & Ref & Ref & & & \\
\hline $41 / 380$ & $>90$ th $(\%)$ & 24.4 & 1.33 & $0.62-2.36$ & 0.458 & & & \\
\hline \multicolumn{9}{|l|}{ Age } \\
\hline $96 / 380$ & 1st quartile & $18.8 \%$ & 0.84 & $0.44-1.53$ & 0.573 & 0.79 & $0.42-1.49$ & 0.467 \\
\hline $185 / 380$ & 2nd-3rd quartiles & 21.6 & 1.00 & Ref & Ref & 1.00 & Ref & Ref \\
\hline $99 / 380$ & 4th quartile & 18.2 & 0.81 & $0.43-1.50$ & 0.494 & 0.79 & $0.42-1.50$ & 0.478 \\
\hline \multicolumn{9}{|l|}{ Gender } \\
\hline $205 / 380$ & Female & $18.0 \%$ & 1.00 & Ref & Ref & 1.00 & Ref & Ref \\
\hline $175 / 380$ & Male & 22.3 & 1.30 & $0.79-2.15$ & 0.304 & 1.35 & $0.81-2.25$ & 0.256 \\
\hline \multicolumn{9}{|c|}{ Population density } \\
\hline $138 / 380$ & High & $21.0 \%$ & 1.00 & Ref & Ref & & & \\
\hline $123 / 380$ & Average & 13.8 & 0.60 & $0.31-1.16$ & 0.130 & & & \\
\hline $119 / 380$ & Low & 25.2 & 1.27 & $0.71-2.27$ & 0.426 & & & \\
\hline \multicolumn{9}{|c|}{ Hospital catchment area } \\
\hline $195 / 380$ & Hospital A & $21.5 \%$ & 2 & $1.04-3.85$ & 0.038 & 2.13 & $1.09-4.13$ & 0.026 \\
\hline $116 / 380$ & Hospital B & 12.1 & 1.00 & Ref & Ref & 1.00 & Ref & Ref \\
\hline $69 / 380$ & Hospital C & 29.0 & 2.97 & $1.39-6.38$ & 0.005 & 3.05 & $1.27-7.34$ & 0.013 \\
\hline \multicolumn{9}{|c|}{ Average income } \\
\hline $244 / 380$ & High & $17.6 \%$ & 1.00 & Ref & Ref & & & \\
\hline $136 / 380$ & Low & 24.3 & 1.50 & $0.90-2.50$ & 0.122 & & & \\
\hline
\end{tabular}

Uni- and multivariate logistic regressions of factors potentially influencing the risk for emergency colon cancer surgery. Age and distance divided in quartiles. Distance to the closest hospital performing CRC surgery was also analysed using a model divided at the 90th percentile 
not affect the risk for emergency surgery. It could be that the biology of the tumour or patient characteristics are more important risk factors for emergency colon cancer surgery.

The small differences in mean distance to hospital found between emergency and electively operated patients strengthens our conclusion that there is no clinically relevant and unbiased correlation between the distance to hospital and the risk for emergency surgery. The non-linearity of differences in prevalence of emergency surgery between the distance quartiles further strengthens this conclusion. It is thus unlikely that our failure to detect an effect of distance on risk for emergency surgery was due to a lack of statistical power.

The difference in proportions of colon cancer surgery performed as an emergency seen in the three hospital catchment areas is more difficult to interpret. It seems unlikely that differences in biological characteristics of tumours or patients could explain a relationship between living in a specific hospital's catchment area and the risk for emergency surgery. It is more likely that the difference between these catchment areas in delay from onset of symptoms or diagnosis to surgery is the cause. However, since there were only three catchment areas represented in this study, it is not possible to draw any firm conclusions regarding the cause of variability. Nevertheless, the large variability in prevalence of emergency surgery between the three catchment areas is an interesting finding that requires further investigation. The lowest percentage emergency surgery was at one of the local hospitals (12\%). Should it be possible to attain a similar figure for the general population of CRC patients, a considerable impact on the overall prognosis of colon cancer would be achieved.

Numerous studies on the relationship between duration of symptoms and prognosis have failed to indicate a worse prognosis for those with long delay between onset of symptoms and treatment [15]; in fact, the opposite seems to be the case $[16,17]$. Patients with long distances to travel to a hospital performing CRC surgery also tend to show up with more advanced tumour stages [18]. The main reason for not seeking medical advice for symptoms of colon cancer is because the patient does not believe the situation is serious and that the problem will disappear spontaneously [19, 20]. The distance to the nearest hospital is unlikely to influence this behaviour since the patient seeks advice at the local healthcare centre first, and this is usually much closer to home than the hospital performing CRC surgery. Subsequent referral for further investigation with coloscopy, $\mathrm{CT}$ etc. is probably more dependent on the general practitioner and local healthcare logistics than on the patient.

If we are to reduce the numbers of emergency surgical procedures for CRC, then we must detect cancer before it gives rise to symptoms. Screening is probably one of the most effective ways of decreasing the prevalence of emergency surgery for colon cancer. It has been shown that distance to the healthcare provider is a barrier when screening for breast cancer [21], and this may also apply to colon cancer screening. If this should be the case, then distance to the screening hospital could have an impact on the risk for emergency surgery in a population where screening is well established.

A limitation of this study is the relatively small number of patients and that only one county was included. The main advantage is that the study was population based and includes all patients who underwent resection surgery in a well-defined area without exclusions. The catchment areas of the three hospitals are strictly defined and healthcare is government funded. There are very few exceptions where private means or insurance policies play a significant role in financing healthcare in this area. Furthermore, distances travelled were measured from the patient's home at the time of their operation to the nearest hospital providing CRC surgery and not on estimations based on zip code centroids.

This study analysed income groups at municipality level only. Since there was a fairly large but non-significant difference in the risk for emergency surgery between the income groups, it would be of interest to investigate the impact of income at the individual level in a larger study population.

\section{Conclusion}

Distance to a hospital providing CRC surgery is not a risk factor for emergency colon cancer surgery. However, when comparing the hospital catchment area with the lowest proportion of CRC procedures performed as an emergency, with the other two hospital catchment areas in this study, the difference in risk was two to threefold. It thus seems likely that there are other factors that determine the risk for emergency colon cancer surgery that we are unable to target with the present dataset and population.

Acknowledgements We would like to thank Google Inc. for allowing us to use Google Maps ${ }^{\mathrm{TM}}$ for distance estimations.

Funding information This study was funded by research grants from Lion's Research Foundation, Umeå University and by regional agreement between Umeå University and Västerbotten County Council (ALF).

\section{Compliance with ethical standards}

Conflict of interest The authors declare that they have no conflict of interest.

Open Access This article is distributed under the terms of the Creative Commons Attribution 4.0 International License (http:// creativecommons.org/licenses/by/4.0/), which permits unrestricted use, distribution, and reproduction in any medium, provided you give appropriate credit to the original author(s) and the source, provide a link to the Creative Commons license, and indicate if changes were made. 


\section{References}

1. Kodeda K, Nathanaelsson L, Jung B, Olsson H, Jestin P, Sjovall A et al (2013) Population-based data from the Swedish Colon Cancer Registry. Br J Surg 100(8):1100-1107

2. Oliphant R, Mansouri D, Nicholson G, McMillan D, Horgan P, Morrison D (2014) Emergency presentation of node-negative colorectal cancer treated with curative surgery is associated with poorer short and longer-term survival. Int J Color Dis 29:591-598

3. McArdle CS, Hole DJ (2004) Emergency presentation of colorectal cancer is associated with poor 5-year survival. Br J Surg 91(5):605-609

4. McArdle CS, McMillan DC, Hole DJ (2006) The impact of blood loss, obstruction and perforation on survival in patients undergoing curative resection for colon cancer. Br J Surg 93:483-488

5. Jestin P, Nilsson J, Heurgren M, Påhlman L, Glimelius B, Gunnarsson U (2005) Emergency surgery for colonic cancer in a defined population. Br J Surg 92(1):94-100

6. Mitchell E, Macdonald S, Campbell NC, Weller D, Macleod U (2008) Influences on pre-hospital delay in the diagnosis of colorectal cancer: a systematic review. Br J Cancer 98(1):60-70

7. Iversen LH, Antonsen S, Laurberg S, Lautrup MD (2009) Therapeutic delay reduces survival of rectal cancer but not of colonic cancer. Br J Surg 96(10):1183-1189

8. Neal RD, Allgar VL (2005) Sociodemographic factors and delays in the diagnosis of six cancers: analysis of data from the "National Survey of NHS patients: Cancer". Br J Cancer 92(11):1971-1975

9. Gunnarsson H, Ekholm A, Olsson LI (2013) Emergency presentation and socioeconomic status in colon cancer. Eur J Surg Oncol 39(8):831-836

10. Hansen RP, Olesen F, Sorensen HT, Sokolowski I, Sondergaard J (2008) Socioeconomic patient characteristics predict delay in cancer diagnosis: a Danish cohort study. BMC Health Serv Res 8:49

11. Chow CJ, Al-Refaie WB, Abraham A, Markin A, Zhong W, Rothenberger DA et al (2015) Does patient rurality predict quality colon cancer care?: a population-based study. Dis Colon Rectum 58(4):415-422
12. SCB Sammanräknad förvärvsinkomst för boende i Sverige den 31/ 12 resp år (antal personer, medel-och medianinkomst samt totalsumma) efter region, kön, ålder och inkomstklass. År 19912015 (n.d.). http://www.statistikdatabasen.scb.se/pxweb/sv/ssd/ START HE HE0110 HE0110A/SamForvInk2/?rxid= 39055bf8-1449-4422-a7dd-81c1ae0b0422

13. The Swedish Institute (2014) Facts about Sweden: health care. Sweden.se

14. van Gijn W, Gooiker GA, Wouters MW, Post PN, Tollenaar RA, van de Velde CJ (2010) Volume and outcome in colorectal cancer surgery. Eur J Surg Oncol 36(Suppl 1):S55-S63

15. Stapley S, Peters TJ, Sharp D, Hamilton W (2006) The mortality of colorectal cancer in relation to the initial symptom at presentation to primary care and to the duration of symptoms: a cohort study using medical records. Br J Cancer 95(10):1321-1325

16. Jullumstro E, Lydersen S, Moller B, Dahl O, Edna TH (2009) Duration of symptoms, stage at diagnosis and relative survival in colon and rectal cancer. Eur J Cancer 45(13):2383-2390

17. Rupassara KS, Ponnusamy S, Withanage N, Milewski PJ (2006) A paradox explained? Patients with delayed diagnosis of symptomatic colorectal cancer have good prognosis. Color Dis 8(5):423-429

18. Massarweh NN, Chiang YJ, Xing Y, Chang GJ, Haynes AB, You YN, Feig BW, Cormier JN (2014) Association between travel distance and metastatic disease at diagnosis among patients with colon cancer. J Clin Oncol 32(9):942-948

19. Courtney RJ, Paul CL, Sanson-Fisher RW, Macrae F, Attia J, McEvoy M (2012) Current state of medical-advice-seeking behaviour for symptoms of colorectal cancer: determinants of failure and delay in medical consultation. Color Dis 14(5):e222-e229

20. Olsson L, Bergkvist L, Ekbom A (2009) Symptom duration versus survival in non-emergency colorectal cancer. Scand J Gastroenterol 39(3):252-258

21. Scoggins JF, Fedorenko CR, Donahue SM, Buchwald D, Blough DK, Ramsey SD (2012) Is distance to provider a barrier to care for Medicaid patients with breast, colorectal, or lung cancer? J Rural Health 28(1):54-62 